\title{
Photoperiod and the regulation of annual and circannual cycles of food intake
}

\author{
BY A. S. I. LOUDON \\ Reproductive Biology Research Group, Institute of Zoology, Zoological Society of London, \\ London NW1 $4 R Y$
}

For wild animals, food availability usually exhibits considerable seasonal fluctuations and as a result dramatic seasonal variations in body weight, fatness and food intake are often observed. Birds and mammals living in the temperate zones or higher latitudes, therefore, time the onset of reproductive activity each year with great precision so that young are produced at the most propitious time of year. Numerous studies have now demonstrated that in such animals seasonal physiological changes governing the reactivation of the reproductive axis are tuned by external environmental change, principally photoperiod (for review, see Bronson, 1988; Bronson \& Heideman, 1994). The annual daylength cycle, thus, represents the most reliable noise-free proximal factor available to entrain seasonal reproductive cycles.

Food intake and body condition are seasonally and photoperiodically regulated in many mammals (Mrosovsky \& Sherry, 1980). The phenomenon has been most extensively investigated in ruminants, scuirid rodents and small mammals, including several species of voles and hamsters (Bartness \& Wade, 1985; Kay, 1985). The present brief review seeks to highlight aspects of the photoperiodic and seasonal regulation of food intake and metabolic cycles by examining their endogenous nature and considering the manner of their photoperiodic regulation. Two related topics will be considered. First, the role of photoperiod change and the endocrine transduction of the photoperiodic signal will be examined in relation to seasonal changes in metabolism and food intake. Second, the endogenous nature of these processes in many organisms will be emphasized. Since the field has now developed a voluminous literature, reviews and major articles are cited for further reference where appropriate.

\section{SEASONAL CHANGES IN BODY CONDITION AND FOOD INTAKE}

\section{Deer}

Wild red deer (Cervus elaphus) undergo marked seasonal changes in body condition, laying down fat during the late summer which is mobilized by males in the autumnal rut and by females over the winter (Mitchell et al. 1976). However, the seasonal cycle of body condition of such animals is not due entirely to the alteration in abundance and scarcity of forage. In red deer, seasonal changes in body condition are also observed when animals are farmed on productive grass pastures (Fennessey et al. 1981; Atajaya et al. 1989). Studies of enhoused deer provided with ad lib. access to consistent diets reveal that the body-weight cycle is associated with an underlying cycle of voluntary food intake (VFI), the VFI cycle (Pollock, 1975; Simpson et al. 1984; Suttie \& Simpson, 1985; Loudon et al. 1989; for review, see Barry et al. 1991). Similar cycles of body condition and food intake have been shown to occur in other temperate or boreal species including reindeer (Rangifer tarandus tarandus; McEwan \& Whitehead, 1970; Ryg \& Jacobsen, 
1982a), moose (Alces alces; Gasaway \& Coady, 1974) and roe deer (Capreolus capreolus; Drozdz et al. 1975). They are also observed in feral and domesticated breeds of sheep, although in the latter case the cycles are attenuated and do not exhibit the high amplitude seen in wild ruminants (Simpson et al. 1984; Kay, 1985).

Under natural conditions the annual peak of VFI in red deer occurs in mid-summer, with a trough in mid-winter (Loudon et al. 1989). The food-intake cycle, therefore, matches the energy requirements for peak lactation in females (Loudon \& Kay, 1984) and deposition of fat reserves before the rut in stags (Mitchell et al. 1976). In intact stags the cycle has a 2-3-fold amplitude; in females a less than 2-fold amplitude (Loudon \& Brinklow, 1992).

Photoperiod is known to regulate the VFI cycle of seasonal deer (Brown et al. 1979; Fig. 1). For instance, red deer maintained on an artificial 6-month photoperiod such that two cycles of long or short daylength occur in one calendar year exhibit two cycles of food intake and body weight gain, i.e. two rhythms of peak intake followed by a trough (Kay, 1979; Simpson et al. 1984). When the cycle is compressed by manipulating the frequency of the photoperiod signal, the peak in appetite lags behind the peak in daylength such that food intake reaches a maximum at a time when photoperiod has started to decrease (Kay, 1979). These seasonal cycles are capable of further photoperiodically-mediated compression. For instance, red deer stags maintained on alternating 2-month periods of artificial photoperiods of $16 \mathrm{~h}$ light (L) $-8 \mathrm{~h}$ dark (D; 16L:8D) followed by $8 \mathrm{~L}: 16 \mathrm{D}$ show a cycle of food intake and antler growth every 4 months (Suttie et al. 1984). Here, the phase-delay in the rhythms of intake is even more marked. (This problem is discussed in more detail (p. 502) in relation to the issue of circannual rhythmicity.)

A number of authors have reported a seasonal reduction in metabolic rate and estimated maintenance energy requirement for deer maintained on winter photoperiods (Silver et al. 1969; McEwan \& Whitehead, 1970; Thompson et al. 1973; Simpson et al. 1978). However, in a recent study of growing red deer calves no significant seasonal difference in resting energy expenditure was detected (Sibbald et al. 1993). In this latter study general energy expenditure was closely correlated with animal activity and animals were generally more active in the summer than the winter. These observations are consistent with other recent studies of metabolic rates in white-tailled deer (Odocoileus virginianus) in which no significant seasonal variation was detected (Pekins et al. 1992). Thus, for deer it remains unclear whether metabolic rate exhibits significant seasonal variation or whether earlier reporțs in the literature of seasonal variation in metabolic rate merely reflected seasonal differences in animal activity and behaviour.

The phasing of the seasonal VFI cycle of deer is largely independent of seasonal changes in gonadal steroid secretion associated with re-activation of the reproductive axis (Fig. 1). For instance, castrated males also exhibit seasonal VFI cycles (Kay, 1979; Ryg \& Jacobsen, 1982b). However, gonadal steroids do modulate the amplitude of the VFI cycle since castrated red deer stags exhibit low-amplitude VFI cycles similar to those observed in females (Kay, 1979; Loudon et al. 1989; Loudon \& Brinklow, 1992). Similarly, in females, ovariectomized oestradiol-implanted female red deer continue to exhibit a normal seasonal body-weight cycle with a peak in late summer and a trough in late winter (A. S. I. Loudon \& H. N. Jabbour, unpublished results). 

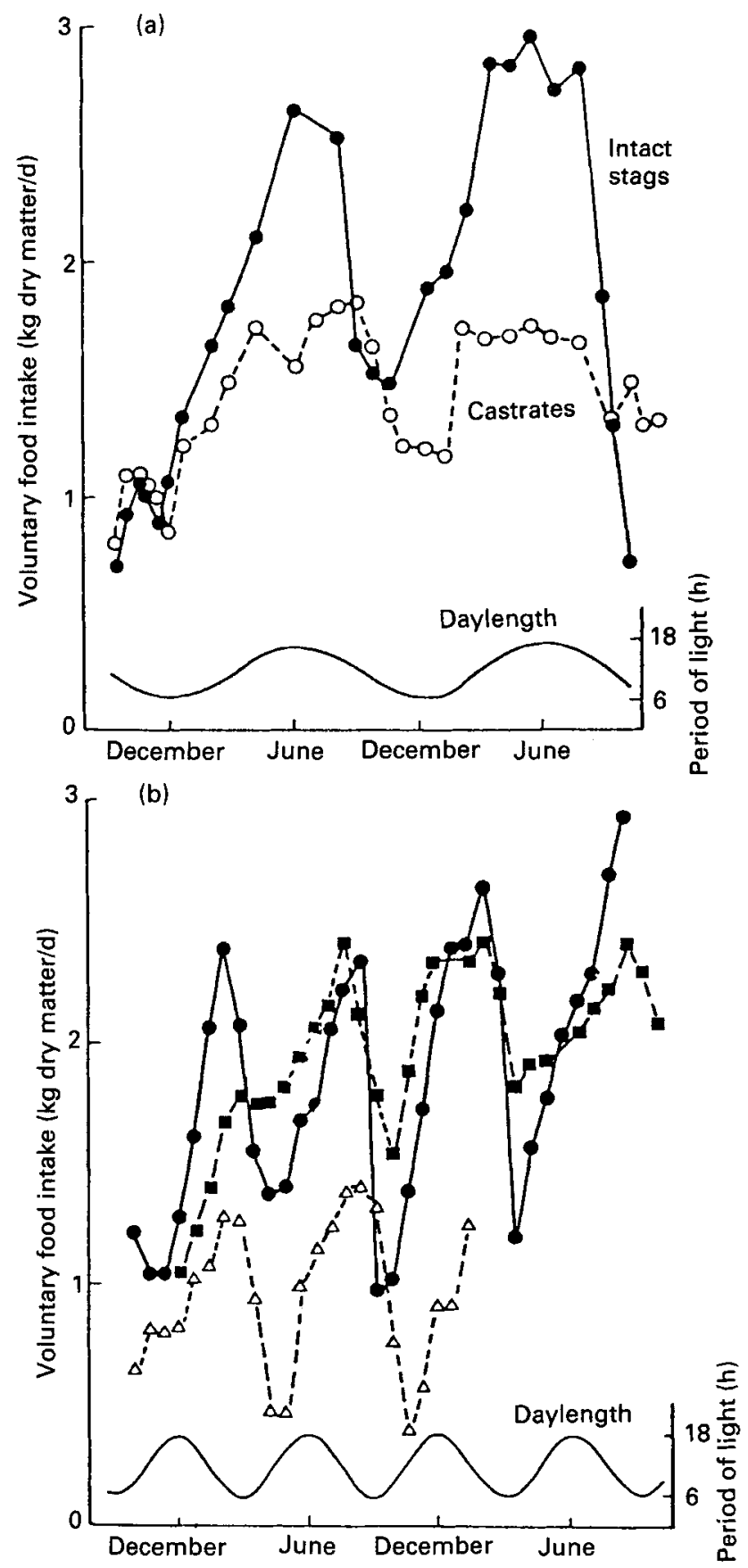

Fig. 1. (a), Voluntary intake of pelleted concentrate by intact $(\bullet)$ or castrate $(O)$ stags penned in natural lighting. (b), Voluntary intake of stags $(\bullet)$, Suffolk $\times$ rams $(\boldsymbol{\square})$ and Soay rams $(\triangle)$ subjected to a 6 -month photoperiod cycle. From Kay, 1979. 


\section{Involvement of the pineal gland}

The pineal gland and its hormone melatonin is a key element in the transduction of the photoperiodic signal in mammals (for review, see Reiter, 1980). The synthesis of melatonin is controlled by light, with the neural transmission of this signal following a circuitous route from the retina to the pineal gland. Light stimulates the retina which in turn transmits information to a number of neural structures, most importantly the hypothalamic suprachiasmatic nuclei (SCN). The SCN in mammals is responsible for the generation of circadian rhythmicity, including the daily secretion of a nocturnal pineal melatonin signal (Rusak \& Zucker, 1979). Seasonal changes in the duration of photoperiod, therefore, result in an alteration in the duration of melatonin secretion providing the animal with an accurate estimate of the duration of night-length throughout the year. A large number of studies have now demonstrated that artificial administration of melatonin to pinealectomized animals can mimic the effects of photoperiods on reproduction (sheep, Bittman et al. 1983; hamsters, Carter \& Goldman, 1983). It is now clear that the pineal gland is a neutral agent, transmitting seasonal photoperiodic information via the melatonin signal which can be used to cue a variety of neuroendocrine responses, including inhibition or activation of the gonadal axis, changes in body weight or the initiation of moulting. The actual response to the signal, therefore, is appropriate to the species and the environment in question.

Treatment of red deer with melatonin alters the annual pattern of growth and food intake. Stags treated with subcutaneous implants of melatonin in spring exhibit an advance in the timing of the breeding season, also reaching their peak weight earlier and losing weight earlier than untreated animals (Webster et al. 1991). Similar observations have been made for female deer. Milne et al. (1990) treated housed adult female red deer with a daily oral melatonin dose from mid-summer and induced a phase shift of approximately 1 month in the timing of the autumnal decline in VFI. The effect of melatonin in advancing the timing of the VFI cycle was also observed in the timing of the moult cycle and onset of the breeding season. These observations are consistent with the view that exogenous melatonin serves to phase-shift all seasonal physiological rhythms.

Few studies have attempted to examine the effects of manipulation of the seasonal appetite cycle of free-ranging mammals. In one such study, grazing red deer were maintained on pastures offering different levels of food availability and treated with melatonin (Heydon et al. 1993). Food intake of grazing animals was measured in the autumn by use of the $n$-alkane marker technique (Mayes et al. 1986) and their grazing behaviour studied. Melatonin treatment resulted in a significant depression by approximately $20 \%$ of VFI for animals grazing on high-availability pastures but had little effect on animals grazing on a more-restricted pasture (Heydon et al. 1993). The reduction of food intake in melatonin-treated deer grazing high-herbage biomasses during the autumn was similar to effects observed in enhoused melatonin-treated animals fed on $a d$ lib. artificial diets (Milne et al. 1990).

Studies of grazing behaviour failed to reveal any significant differences between treated and control animals with respect to feeding rate (bites per minute). In such circumstances, melatonin-dependent reductions in food intake may be modulated by variation in the duration of time spent grazing per day rather than the instantaneous feeding rate which may be optimized for any given level of food availability. Melatonin also advanced the timing of the onset of the breeding season, as has previously been shown for this species (Adam \& Atkinson, 1984; Adam et al. 1986; Milne et al. 1990). In this study the timing of the offset of the breeding season was also advanced such that the 
total duration of the breeding season was not significantly different from that of untreated animals. These observations provide further support for the idea that melatonin treatment serves to phase-shift underlying circannual rhythms (Loudon \& Brinklow, 1992). A general conclusion is that the expression of seasonal appetite changes in free-ranging grazing animals may depend upon a complex interaction between food availability and feeding behaviour such that appetite cycles may only be manifested in wild populations under conditions of high food availability or at certain stages of the annual cycle.

\section{Rodents}

In muroid rodents the photoperiodic regulation of appetite and body weight exhibits considerable species variation (Dark \& Zucker, 1985). The Syrian hamster (Mesocricetus auratus) has been extensively investigated (for review, see Bartness \& Wade, 1985). In common with other hamster species, this animal is a long-day breeding mammal with a re-activation of the gonadal axis in response to lengthening photoperiods. Syrian hamsters exhibit their minimal body weight during long photoperiods, at which time they have low fat reserves. Following exposure to short photoperiods, their gonads regress and body weight increases (Hoffman \& Reiter, 1966; Bartness \& Wade, 1984; Bartness et al. 1985). This photoperiodically-mediated increase in body weight is almost entirely associated with the deposition of fat and is largely independent of changes in gonadal steroid secretion since castration reduces the amplitude of the photoperiodic effect by only 10-15\% (Bartness \& Wade, 1984; Wade \& Bartness, 1984a). These changes in body condition are associated with a photoperiodically-mediated overall change in energy metabolism; somewhat paradoxically, short photoperiods stimulate brown adipose tissue growth and thermogenic potential in Syrian hamsters (McElroy \& Wade, 1986). Short daylengths also cause an increase in food intake, although the amplitude of the increase over long photoperiods is less than $20 \%$. Here, in contrast to deer (see p. 496), seasonal changes in body weight are primarily attributable to alterations in energy metabolism (Bartness \& Wade, 1984), rather than high-amplitude VFI cycles. Treatment of long-day-housed hamsters with melatonin is effective in mimicking the effects of short photoperiods on weight gain and energy metabolism (Bartness \& Wade, 1984; Wade \& Bartness, 1984a).

In contrast to the Syrian hamster, Siberian hamsters (Phodopus sungorus) and meadow voles (Microtus pennsylvanicus) lose weight and have a reduced food intake and energy expenditure when placed in short photoperiods (Heldmaier \& Steinlechner, 1981a; Dark \& Zucker, 1983; Dark et al. 1983). These changes can also be mimicked by treatment with melatonin (Bartness \& Wade, 1985). Siberian hamsters commonly lose $20-25 \%$ of their body weight on short photoperiods, with almost all of this weight loss being in the form of lipid reserves (Wade \& Bartness, 1984b). At first sight these differences appear to be paradoxical. However, a key feature of the biology of the smaller Siberian hamsters is that unlike Syrian hamsters they do not hibernate. Phodopus reduces its body mass at a time when food supply is decreasing and the harsh Siberian winter is approaching, but by so doing may be able to reduce overall winter maintenance requirements.

The scaling effects of metabolic rate with body size would result in stored fat reserves providing only very short-term energy stores for such an animal. However, shortphotoperiod-housed Siberian hamsters exhibit the phenomenon of daily torpor, whereby 
body temperature is reduced to approximately $17^{\circ}$ for up to $8 \mathrm{~h}$ resulting in significant energy savings (Heldmaier \& Steinlechner, 1981b). Such photoperiodically-mediated inductions of torpor can be blocked by the injection of prolactin (Ruby et al. 1993), a hormone normally secreted only during long photoperiods in seasonal mammals (for review, see Curlewis, 1992). In addition, Siberian hamsters are avid storers of seeds in their burrows and, therefore, may be able to counteract the effect of depleted body energy stores (Bartness \& Wade, 1985). Thus, by storing food, engaging the mechanisms controlling torpor biology and by reducing food intake and body weight, Siberian hamsters are able to survive in extreme winter conditions.

In short-lived muroid rodents, food intake and seasonal metabolic changes are primarily regulated by photoperiodic change. Such species are generally characterized by long breeding seasons with the production of several sequential litters. Under long photoperiods animals remain continuously reproductively active and do not exhibit spontaneous changes in food intake and metabolism. The only expression of an endogenous rhythm is seen if animals are housed under persistent short photoperiodic stimulation. Initially such photoperiods cause gonadal regression, but after $2-3$ months animals will spontaneously undergo full gonadal recrudescence with concomitant changes in metabolism, and remain reproductively competent thereafter. Thus, endogenous rhythmicity is confined to a uni-directional change.

An intriguing feature of the biology of many rodents such as voles is that the pattern of postnatal growth and development is partially entrained by photoperiodic influences experienced by the fetus in utero (Horton, 1984, 1985; Lee \& Zucker, 1988). Vole pups born at the beginning of the breeding season undergo rapid somatic and reproductive development, achieve puberty by 2 months of age and produce several litters before undergoing reproductive involution in response to shortening photoperiods. In contrast, offspring born at the end of the breeding season exhibit slowed growth rates, deposit fat reserves, grow a thick winter pelage and remain reproductively inactive until the commencement of the next breeding season. The underlying mechanisms involved have been revealed in experiments in which montane voles (Microtus montanus) were gestated under either long (18L:6D) or short photoperiods (10L:14D) and then switched to an identical intermediate photoperiod (14L:10D) at birth (Horton, 1984). Pups exhibited a pattern of growth reflecting the photoperiod experienced by the mother during gestation. In these and other experiments on meadow voles (Lee \& Zucker, 1988), vole mothers clearly communicated information about the daylength to their pups, influencing pup responsiveness postnatally. It has now been established that a major component of the prenatal entraining signal is maternal melatonin, which may be assumed to cross the placental barrier. Treatment of long-day-housed females with melatonin mimics the effects of gestational short photoperiods and results in a decrease in preweaning weight gain, delays testicular development and causes early growth of winter pelage (Lee et al. 1989).

\section{THE SEASONAL REGULATION OF BODY WEIGHT \\ AND CIRCANNUAL RHYTHMS}

\section{Compensatory weight change}

Although seasonal cycles of body-weight gain and loss are characterized by photoperiodically-mediated hyperphagia and anorexia, several lines of evidence support the 
idea that changes in body weight and fat content of mammals are not simply a direct consequence of changing food intake. This phenomenon is most strikingly demonstrated in scuirid rodents such as the ground squirrels which exhibit endogenous seasonal rhythms of body mass, food intake and hibernation, even when kept under constant conditions (Pengelley, 1957; Davis, 1976). For instance, ground squirrels deprived of food for extended intervals either side of the weight gain or loss portion of the cycle and then allowed to re-feed will overeat until they have recovered a seasonally appropriate body mass (Heller \& Poulson, 1970; Mrosovsky \& Fisher, 1970; Barnes \& Mrosovsky, 1974), at which point they will then continue to exhibit appropriately-phased cycles. In red deer the spring-time rise in VFI is largely suppressed by treatment with the dopamine agonist bromocriptine, but treated animals still show a seasonal rise in body weight (Curlewis et al. 1988b). Seasonal cycles of food intake and body weight are generally observed to be out of phase with each other, with body weight either lagging behind the VFI cycle (deer; Loudon et al. 1989) or being in advance of the cycle (ground squirrels, Pengelley \& Admundson, 1974; Siberian hamsters, Bartness \& Wade, 1985), lending further support to the idea that weight changes are not necessarily a direct consequence of changing VFI. Ground squirrels prevented from increasing food intake from the nadir of the winter appetite cycle still gain weight (Dark et al. 1986), while surgical removal of fat pad stores in mid-summer results in spontaneous increase in food intake and the rapid restoration of a seasonally appropriate body weight (Dark et al. 1984). Taken together, these findings suggest that wild animals are capable of remarkable precision in the regulation of the phase of seasonal metabolic cycles and that rapid adjustment of body weight and conditions can take place as a result of altered patterns of energy expenditure or VFI.

\section{Circannual rhythms}

Long-lived species, including non-human primates, ruminants, squirrels, marmots, bats and seasonal carnivores, differ from short-lived rodents in that they manifest persistent rhythmicity even when maintained under constant conditions. These rhythms have a period of approximately 12 months and have been described as circannual rhythms (Gwinner, 1986a). They have been most extensively investigated in birds (Gwinner, 1986b; Gwinner \& Dittami, 1990); in general the neuroanatomical basis for the control of these rhythms is very poorly understood (Zucker \& Dark, 1986; Zucker et al. 1992). It is appropriate to regard seasonal cycles of food intake and body condition as manifestations of circannual rhythms, tuned by an external photoperiodic signal. For example, red deer calves kept from birth on constant long days (18L:6D) for 18 months exhibit seasonal rhythms of VFI and prolactin secretion which have similar phasing to those of control animals housed on natural photoperiods (Brinklow \& Loudon, 1990). Thus, although seasonal rhythmicity of reproduction and metabolism in deer can be manipulated by photoperiod change and melatonin treatment, rhythmicity is endogenous and does not depend on environmental change. The nature of the linkage between seasonal reproductive and metabolic changes is revealed in a comparison between two closelyrelated species, the red deer and Père David's deer (Elaphurus davidianus). These two species will hybridize and have an identical chromosomal karyotype. Although both species have an identical duration to the breeding season, the onset and termination of the season are phase-advanced in the Père David's deer by about $90 \mathrm{~d}$ (Curlewis et al. 
1988a). This advance in breeding season is associated with significant advances in the phase of the VFI cycle, prolactin secretion and the pelage cycle (Loudon et al. 1989). The Père David's deer has undergone a phase-advance in the entire circannual physiological axis.

The body-weight cycles and food intake of hibernating ground squirrels have been extensively studied (Pengelley \& Amundson, 1974; Davis, 1976). Although these animals exhibit high-amplitude seasonal-weight cycles associated with the deposition of substantial fat reserves, an unexpected feature of their biology is their apparent resistance to artificial photoperiodic manipulations (Pengelley \& Amundson, 1974). In contrast to most seasonal mammals, ground squirrels do not respond to the abrupt artificial transitions from long to short photoperiods but persist in showing endogenous seasonal rhythms of body weight and reproductive activity (Davis, 1976). In their natural state, golden-mantled ground squirrels (Spermophilus lateralis and Spermophilus saturatus) live above ground for approximately 6 months and then hibernate underground in complete darkness for a further 6 months (Kenagy, 1987). It is now known that the body-weight cycle of these animals can be entrained by photoperiod, but only when they are subjected to a close mimic of the natural environmental changes of photoperiod for 6 months followed by 6 months of complete darkness (Zucker et al. 1992). Here, the endogenous circannual rhythm is of such strength that it can only be entrained by carefully managed photoperiod cycles.

In contrast to ground squirrels, the conspicuous seasonal rhythms of deer are more amenable to photoperiodic manipulation and this has enabled the relationship between the entraining environmental signal (Zeitgeber) and the underlying circannual rhythm to be explored. In experiments with sika deer (Cervus nippon) the annual rhythms of testis development and the growth of the antler (a steroid-dependent process) can be altered by manipulation of the photoperiodic environment. Under constant conditions the antler cycle of the sika deer exhibits a period of approximately 11 months (Goss, 1984). This cycle can be entrained to artificial photoperiod changes (Goss, 1969a,b). As the driving cycle frequency is increased progressively to 6,4 and 3 months so the antler cycle becomes progressively phase-delayed (i.e. it lags behind the entraining signal). Conversely, when the entraining signal is extended to 24 months, the antler cycle of sika deer exhibits a phase-advance. Similar observations have been made for appetite change of red deer stags driven by high-frequency Zeitgebers (see p. 496). These results in deer are exactly as would be predicted from the operation of an underlying circannual oscillator (Gwinner, 1986a). As the oscillator is driven faster by a more-frequent entraining signal it phase-lags behind the Zeitgeber; driven slower it phase-advances.

An impressive example of the operation of a circannual rhythm is seen in the Axis deer (Axis axis), the most southerly of the old-world deer species. In a study of a captive population maintained at latitude $52^{\circ} \mathrm{N}$, individual animals within the population exhibited free-running circannual antler cycles but out of phase with other members of the herd (Loudon \& Curlewis, 1988; Fig. 2). The cycles of individual animals were resistant to melatonin treatment and, therefore, may provide an example of circannual rhythms of reproduction and body weight which have become uncoupled from the influence of a pineal-dependent photoperiodic Zeitgeber. In this population, freerunning circannual rhythms may persist for the life-time of individual animals but in an asynchronous manner and out of phase with other individuals in the herd.

The persistence of circannual rhythmicity in seasonal mammals and the recognition 


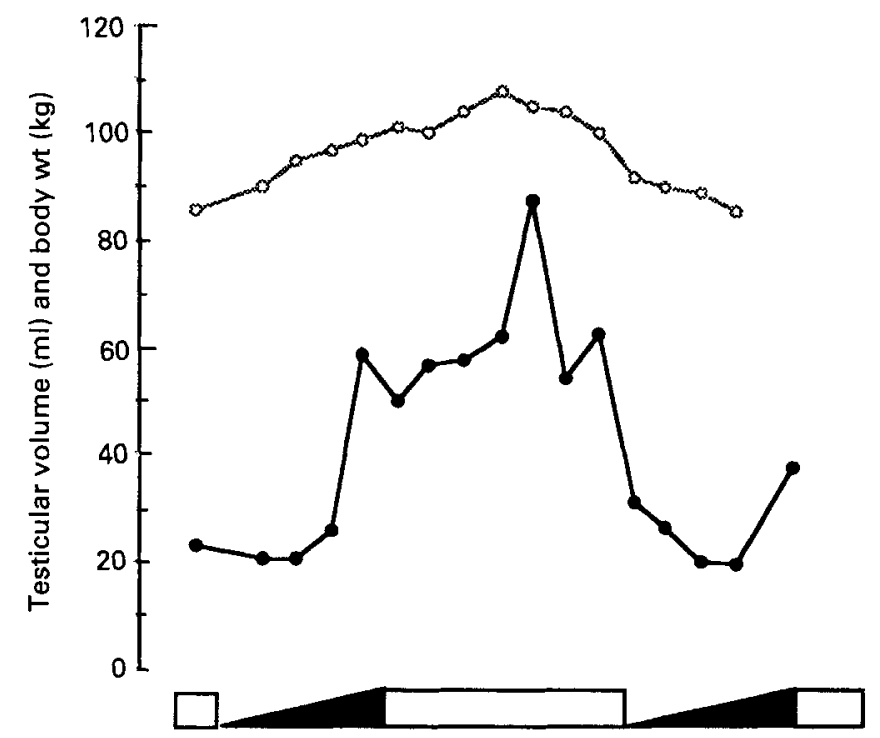

Month... ASONDJFMAMJJASONDJF
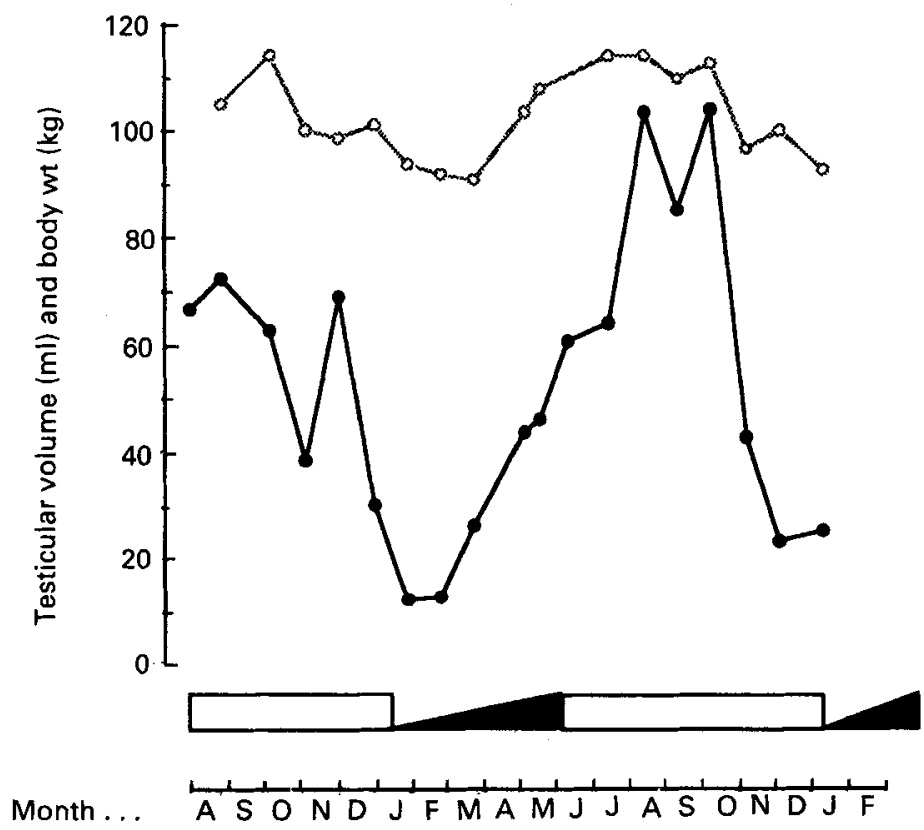

Fig. 2. Circannual rhythms in testis size $(\bullet)$ and body weight $(O)$ in two adult Axis deer stags maintained out of doors at $52^{\circ} \mathrm{N}$ and studied over the same time period. The antler cycle is shown as period of growth $(\mathbf{D})$ and hard horn (ㅁ). Data from Loudon \& Curlewis (1988). 
that such rhythms are a feature of the biology of many tropical organisms raises a final important issue. Hair growth is one of the most conspicuous rhythms in seasonal mammals. In man, hair growth is also seasonal (Randall, 1991). This begs the question as to whether studies of seasonal biology in animals may have more general significance for the physiology of man (see Prentice \& Cole, 1994).

\section{REFERENCES}

Adam, C. L. \& Atkinson, T. (1984). Effect of feeding melatonin to red deer (Cervus elaphus) on the onset of the breeding season. Journal of Reproduction and Fertility 72, 463-466.

Adam, C. L., Moir, C. E. \& Atkinson, T. (1986). Induction of early breeding in red deer (Cervus elaphus) by melatonin. Journal of Reproduction and Fertility 75, 569-573.

Atajaya, A. M., Wilson, P. R., Purchas, R. W., Hay, R. J. M., Hodgson, J. \& Barry, T. N. (1989). A study of early venison production from farmed red deer. Proceedings of the New Zealand Society of Animal Production 49, 25-27.

Barnes, D. C. \& Mrosovsky, N. (1974). Body weight regulation in ground squirrels and hypothalamicallylesioned rats: slow and sudden set point changes. Physiology and Behaviour 12, 251-258.

Barry, T. N., Suttie, J. M., Milne, J. A. \& Kay, R. N. B. (1991). Control of food intake in domesticated deer. In Physiological Aspects of Digestion and Metabolism in Ruminants. Proceedings of the Seventh International Symposium on Ruminant Physiology, pp. 385-401 [T. Tsuda, Y. Sasaki and R. Kawashima, editors]. San Diego: Academic Press.

Bartness, T. J., Bittman, E. L. \& Wade, G. N. (1985). Paraventricular nucleus lesions exaggerate dietary obesity but block photoperiod-induced weight gains and suspension of oestrous cyclicity in Syrian hamsters. Brain Research Bulletin 14, 427.

Bartness, T. J. \& Wade, G. N. (1984). Photoperiodic control of body weight and energy metabolism in Syrian hamsters (Mesocricetus auratus): Role of pineal gland, melatonin, gonads and diet. Endocrinology 114, $492-498$.

Bartness, T. J. \& Wade, G. N. (1985). Photoperiodic control of seasonal body weight cycles in hamsters. Neuroscience and Behavioural Reviews 9, 599-612.

Bittman, E. L., Dempsey, R. J. \& Karsch, F. J. (1983). Pineal melatonin drives the reproductive response to daylength in the ewe. Endocrinology 113, 2276-2283.

Brinklow, B. R. \& Loudon, A. S. I. (1990). Development of seasonal thythms in a long-lived ungulate: the red deer. Journal of Interdisciplinary Cycle Research 21, 173-175.

Bronson, F. H. (1988). Mammalian reproductive strategies: genes, photoperiod and latitude. Reproduction Nutrition Développement 28, 335-347.

Bronson, F. H. \& Heideman, P. D. (1994). Seasonal regulation of reproduction in mammals. In The Physiology of Reproduction, 2nd ed. [E. Knobil and J. D. Neill, editors]. New York: Raven Press Ltd.

Brown, W. B., Forbes, J. M., Goodall, E. D., Kay, R. B. N. \& Simpson, A. M. (1979). Effects of photoperiod on food intake, sexual condition and hormone concentration in stags and rams. Proceedings of the Physiological Society 296, 58P-59P.

Carter, D. S. \& Goldman, B. D. (1983). Antigonadal effects of timed melatonin infusion in pinealectomised male Djungarian hamsters (Phodopus sungorus sungorus): Duration is the critical parameter. Endocrinology 113, 1261-1267.

Curlewis, J. D. (1992). Seasonal prolactin secretion and its role in seasonal reproduction: a review. Reproduction Fertility and Development 4, 1-23.

Curlewis, J. D., Loudon, A. S. I. \& Coleman, A. P. M. (1988a). Oestrous cycles and the breeding season of the Père David's deer (Elaphurus davidianus). Journal of Reproduction and Fertility 82, 119-126.

Curlewis, J. D., Loudon, A. S. I., Milne, J. A. \& McNeilly, A. S. (1988b). Effects of chronic long-acting bromocriptine treatment on body weight, voluntary food intake, coat growth and breeding season in non-pregnant red deer hinds. Journal of Endocrinology 119, 413-420.

Dark, J., Forger, N. G. \& Zucker, I. (1984). Rapid recovery of body mass after surgical removal of adipose tissue in ground squirrels. Proceedings of the National Academy of Sciences, USA 81, 2270-2272.

Dark, J., Forger, N. G. \& Zucker, I. (1986). Regulation and function of lipid mass during the annual cycle of the golden-mantled ground squirrel. In Living in the Cold; Physiological and Biochemical Adaptations, pp. 445-451 [H. C. Heller, X. J. Musacchia and L. C. H. Wang, editors]. New York: Elsevier. 
Dark, J. \& Zucker, I. (1983). Short photoperiods reduce energy requirements of the meadow vole (Microtus pennsylvanicus). Physiology and Behaviour 31, 699-702.

Dark, J. \& Zucker, I. (1985). Seasonal cycles in energy balance: Regulation by light. Annals of the New York Academy of Sciences 453, 170-181.

Dark, J., Zucker, I. \& Wade, G. N. (1983). Photoperiodic regulation of body mass, food intake and reproduction in Meadow Voles. American Journal of Physiology 245, R334-R338.

Davis, D. E. (1976). Hibernation and circannual rhythms of food consumption in marmots and ground squirrels. Quarterly Reviews of Biology 51, 477-515.

Drozdz, A., Weiner, J., Gebczynska, Z. \& Krasinska, M. (1975). Some bioenergetic parameters of wild ruminants. Polish Ecological Study 1, 85-101.

Fennessey, P. F., Moore, G. H. \& Corson, I. D. (1981). Energy requirements of red deer. Proceedings of the New Zealand Society of Animal Production 41, 167-173.

Gasaway, W. C. \& Coady, J. W. (1974). Review of energy requirements and rumen fermentation in moose and other ruminants. Naturaliste Canadien 101, 227-262.

Goss, R. J. (1969a). Photoperiodic control of antler cycles in deer. I. Phase shift and frequency changes. Journal of Experimental Zoology 170, 311-324.

Goss, R. J. (1969b). Photoperiodic control of the antler cycles in deer. II. Alteration in amplitude. Journal of Experimental Zoology 171, 223-234.

Goss, R. J. (1976). Photoperiodic control of antler cycles in deer. III. Decreasing versus increasing daylengths. Journal of Experimental Zoology 197, 307-312.

Goss, R. J. (1984). Photoperiodic control of antler cycles in deer. VI. Circannual rhythms on altered daylengths. Journal of Experimental Zoology 230, 265-271.

Gwinner, E. (1986a). Circannual Rhythms. Berlin: Springer.

Gwinner, E. (1986b). Circannual rhythms in the control of avian migrations. Advances in the Study of Behaviour 16, 191-228.

Gwinner, E. \& Dittami, J. (1990). Endogenous reproductive rhythms in a tropical bird. Science 249, 906-908.

Heldmaier, G. S. \& Steinhlechner, S. (1981a). Seasonal control of energy requirements for thermoregulation in the Djungarian hamster (Phodopus sungorus) living in a natural photoperiod. Journal of Comparative Physiology 142, 429-437.

Heldmaier, G. S. \& Steinlechner, S. (1981b). Seasonal pattern of short daily torpor in the Djungarian hamster, Phodopus sungorus. Oecologia 48, 265-270.

Heller, H. C. \& Poulson, T. L. (1970). Circannian rhythms. II. Endogenous and exogenous factors controlling reproduction and hibernation in chipmunks (Eutamias) and ground squirrels (Spermophilus). Comparative Biochemistry and Physiology 33, 357-383.

Heydon, M. J., Sibbald, A. M., Milne, J. A., Brinklow, B. R. \& Loudon, A. S. I. (1993). The interaction of food availability and endogenous physiological cycies on the grazing ecology of red deer hinds (Cervus elaphus). Functional Ecology 7, 216-222.

Hoffman, R. A. \& Reiter, R. J. (1966). Pineal gland: influence on gonads of male hamsters. Science 148, 1609-1611.

Horton, T. H. (1984). Growth and reproductive development of male Microtus montanus is affected by the prenatal photoperiod. Biology of Reproduction 31, 499-504.

Horton, T. H. (1985). Cross-fostering of voles demonstrates in-utero effects of photoperiod. Biology of Reproduction 33, 934-939.

Kay, R. N. B. (1979). Seasonal changes of appetite in deer and sheep. Agricultural Research Council Research Reviews 5, 13-15.

Kay, R. N. B. (1985). Seasonal variation of appetite in ruminants. In Recent Advances in Animal Nutrition [W. Haresign, editor]. London: Butterworths.

Kenagy, G. J. (1987). Energy allocation for reproduction in the golden mantled ground squirrel. In Reproductive Energetics in Mammals, pp. 259-272 [A. S. I. Loudon and P. A. Racey, editors]. Oxford: Clarendon Press.

Lee, T. M., Spears, N., Tuthill, C. R. \& Zucker, I. (1989). Maternal melatonin treatment influences rates of neonatal development of meadow vole pups. Biology of Reproduction 40, 495-502.

Lee, T. M. \& Zucker, I. (1988). Vole infant development is influenced perinatally by maternal photoperiodic history. American Journal of Physiology 255, R831-R838.

Loudon, A. S. I. \& Brinklow, B. R. (1992). Reproduction in deer: adaptations for life in seasonal environments. In The Biology of Deer, pp. 261-278 [R. D. Brown, editor]. New York: Springer-Verlag. 
Loudon, A. S. I. \& Curlewis, J. D. (1988). Cycles of antler and testicular growth in an aseasonal tropical deer (Axis). Journal of Reproduction and Fertility 83, 729-738.

Loudon, A. S. I. \& Kay, R. N. B. (1984). Lactational constraints on a seasonally breeding mammal: the red deer. Symposia of the Zoological Society of London 51, 233-252.

Loudon, A. S. I., Milne, J. D., Curlewis, J. D. \& McNeilly, A. S. (1989). A comparison of the seasonal hormone changes and patterns of growth, voluntary food intake and reproduction in juvenile and adult red deer (Cervus elaphus) and Père David's deer (Elaphurus davidianus). Journal of Endocrinology 122, 733-745.

McElroy, J. F. \& Wade, G. N. (1986). Short photoperiod stimulates brown adipose tissue growth and thermogenesis but not norepinephrine turnover in Syrian hamsters. Physiology and Behaviour 37, 307-311.

McEwan, E. H. \& Whitehead, P. E. (1970). Seasonal changes in energy and nitrogen intake in reindeer and caribou. Canadian Journal of Zoology 48, 905-913.

Mayes, R. W., Lamb, C. S. \& Colgrove, P. M. (1986). The use of dosed and herbage n-alkanes as markers for the determination of herbage intake. Journal of Agricultural Science, Cambridge 107, 161-170.

Milne, J. A., Loudon, A. S. I., Sibbald, A. M. \& McNeilly, A. S. (1990). Effects of melatonin and a dopamine agonist and antagonist on seasonal changes in voluntary food intake, reproductive activity and plasma concentrations of prolactin and tri-iodothyronine in red deer hinds. Journal of Endocrinology 125، 241-249.

Mitchell, B. McCowan, D. \& Nicholson, I. A. (1976). Annual cycles of body weight and condition in Scottish red deer (Cervus elaphus). Journal of Zoology 180, 107-127.

Mrosovsky, N. \& Fisher, K. C. (1970). Sliding set-points for body weight in ground squirrels cluring the hibernation season. Canadian Journal of Zoology 48, 241-247.

Mrosovsky, N. \& Sherry, D. F. (1980). Animal anorexias. Science 207, 837-842.

Pekins, P. J., Mautz, W. W. \& Kanter, J. J. (1992). Reevaluation of the basal metabolic rate cycle in white-tailed deer. In The Biology of Deer, pp. 418-428 [R. D. Brown, editor]. New York: Springer-Verlag.

Pengelley, E. T. (1957). Onset and cessation of hibernation under constant temperature and light in the golden-mantled ground squirrel (Citellus lateralis). Nature 180, 1371-1372.

Pengelley, E. T. \& Amundson, S. J. (1974). Circannual rhythmicity in hibernating animals. In Circannual Clocks: Annual Biological Rhythms, pp. 96-160 [E. T. Pengelley, editor]. New York: Academic Press.

Pollock, A. M. (1975). Seasonal changes in appetite and sexual condition in red deer stags maintained on a six month photoperiod. Journal of Physiology 244, 95P-96P.

Prentice, A. M. \& Cole, T. J. (1994). Seasonal changes in growth and energy status in the Third World. Proceedings of the Nutrition Society $\mathbf{5 3}, 509-519$.

Randall, V. A. (1991). Seasonal changes in human hair growth. British Journal of Dermatology 124, 146-151.

Reiter, R. J. (1980). The pineal and its hormones in the control of reproduction in mammals. Endocrine Reviews 1, 109-131.

Ruby, N. F., Nelson, R. J., Licht, P. \& Zucker, I. (1993). Prolactin and testosterone inhibit torpor in Siberian hamsters. American Journal of Physiology 264, R123-R128.

Rusak, B. \& Zucker, I. (1979). Neural regulation of circadian rhythms. Physiological Reviews 59, 449-526.

Ryg, M. \& Jacobsen, E. (1982a). Seasonal changes in growth rate, feed intake, growth hormone and thyroid hormones in young male reindeer (Rangifer tarandus). Canadian Journal of Zoology 60, 15-23.

Ryg, M. \& Jacobsen, E. (1982b). Effects of castration on growth and food intake in young male reindeer (Rangifer tarandus tarandus). Canadian Journal of Zoology 60, 942-945.

Sibbald, A. M., Fenn, P. D., Kerr, W. G. \& Loudon, A. S. I. (1993). The influence of birth date on the development of seasonal cycles in red deer hinds (Cervus elaphus). Journal of Zoology 230, 593-607.

Silver, H., Colovos, N. F., Holter, J. B. \& Haynes, H. H. (1969). Fasting metabolism in white-tailed deer. Journal of Wildlife Management 33, 490-498.

Simpson, A. M.. Suttie. J. M. \& Kay, R. N. B. (1984). The influence of artificial photoperiod on the growth, appetite and reproductive status of male red deer and sheep. Animal Reproduction Science 6, 29.1-299.

Simpson, A. M., Webster, A. J. F., Smith, J. S. \& Simpson, C. A. (1978). The efficiency of utilization of dietary energy for growth in sheep (Ovis) and red deer (Cervus elaphus). Comparative Biochemistry and Physiology 59A, 95-99.

Suttie, J. M., Corson. I. D. \& Fennessey, P. F. (1984). Voluntary intake, testis development and antler growth patterns of male red deer under a manipulated photoperiod. Proceedings of New Zealand Society of Animal Production 44, 167-170.

Suttie, J. M. \& Simpson, A. M. (1985). Photoperiodic control of appetite, growth, antlers and endocrine status of red deer. Bulletin of the Royal Society of New Zealand 22, 429-432. 
Thompson, C. B., Holter, J. B., Hayes, H. H., Silver, H. \& Urban, W. E. (1973). Nutrition of white-tailed deer. 1. Energy requirements of fawns. Journal of Wildlife Management 37, 301-311.

Wade, G. N. \& Bartness, T. J. (1984a). Seasonal obesity in Syrian hamsters: effects of age, diet, photoperiod and melatonin. American Journal of Physiology 247, R328-R334.

Wade, G. N. \& Bartness, T. J. (1984b). Effects of photoperiod and gonadectomy on food intake, body weight and body composition in Siberian hamsters. American Journal of Physiology 246, R26-R30.

Webster, J. R., Suttie, J. M. \& Corson, I. D. (1991). Effects of melatonin implants on reproductive seasonality of male red deer (Cervus elaphus). Journal of Reproduction and Fertility 92, 1-11.

Zucker, I. \& Dark, J. (1986). Neuroendocrine substrates of circannual rhythms in ground squirrels. In Living in the Cold; Physiological and Biochemical Adaptations, pp. 351-360 [H. C. Heller, X. J. Musacchia and L. C. H. Wang, editors]. New York: Elsevier.

Zucker, I., Lee, T. M. \& Dark, J. (1992). The suprachiasmatic nucleus and annual rhythms of mammals. In Suprachiasmatic Nucleus: The Mind's Clock, pp. 246-260 [D. C. Klein, R. Y. Moore and S. M. Reppert, editors]. Oxford: Oxford University Press. 